\title{
The Research and Development of New Filling Material with High Water Retention and Dilatation
}

\author{
YANG Chao ${ }^{1, a}$,GUO Lijie ${ }^{1, b}$,WANG Jie ${ }^{2, \mathrm{c}}$,HOU Guoquan ${ }^{1, \mathrm{~d}}$ and \\ XU Wenyuan ${ }^{1, e}$ \\ ${ }^{1}$ Beijing General Research Institute of Mining and Metallurgy, Beijing 102628, China \\ ${ }^{2}$ Shandong University of Technology, Zibo, Shandong Province 255000, China \\ ayclql@163.com, bljguo264@126.com, 'cwjie@sdut.edu.cn, ${ }^{\mathrm{d}}$ houguoquan@126.com, \\ exwy156@163.com
}

\begin{abstract}
Keywords: New filling cementing material, Dilatation, High water retention, Ettringite (Aft), Microstructure

Abstract. This paper analyzed the mechanism of dilatation and high water retention of the independently researched new cementing material. It was proved by the experiment of dilatation and water retention behavior that the maximum water-solid ratio of this new material are 3:1 and the maximum volume dilatation rate of the backfill are $50.02 \%$. The experiment of compression strength shows that the maximum uniaxial compression strength of the backfill can reach up to $9.73 \mathrm{MPa}$. The relationship of uniaxial compression strength with flexural strength and tensile strength were fitted by the least square method. Moreover, this paper explained the increasing law of the strength of the backfill in principal by analyzing its microstructure with Scanning Electron Microscope(SEM).
\end{abstract}

\section{Introduction}

Underground mining provides industrial production with all sorts of raw materials. However, traditional underground mining would destroy the in Situ balance by creating goaf area, which is the major hazard to the safety of mining production, personnel and properties. It would also destruct ecological environment by causing the earth`s surface sinking [1]. Consequently, we should uphold the 'Green Mining' method - to achieve the goals of sustainable development [2], which require low mining rate, high mineral utilization rate and less mineral waste rate by upholding the idea of mining technology innovation and ecological environment conservation and by persist to integrate mineral development and utilization with ecological environment conservation. With its efficacy of environmental conservation and increasing recovery rate in the premise of insuring safety [3], backfill mining is one of the most important core technology in green mining system.

The behavior of filling materials in backfill mining determines directly the quality of the backfill and the mining safety. Cement is used in backfill mining, and it is the most widely used cementing materials in concrete products. However, there is a big difference between the impletion of cement in backfill mining and concrete products. The water content in filling materials are comparatively larger (the ratio of cementing materials and water in normal filling slurry are 1:3). In order to retain water and prevent the filling slurry from water bleeding, a large amount of cement are needed in backfill mining, which will lead to the increasing of mining costs. Meanwhile, cement used as the cementing material in the filling slurry will cause bleeding. And the contractility of the backfill makes it difficult to contact the roof rock. Therefore, a cheap filling cementing material with high water retention and dilatation can better fulfill the need of backfill mining.

Our research produced new filling cementing material which has good application, with high water retention, dilatation and high strength by using industrial smelting residue, lime, gypsum and related additives. With this filling material, the quality of backfill can be improved and the mining safety can be insured. 


\section{Material Composition}

The new filling cementing material is mainly composed by lime, gypsum, smelting residue and additives. The basic character of each material are as follow:

Lime

Being one of the raw material of the new filling cementing material, lime has strong hydration ability. The hydration of lime releases large quantity of hit at high rate, and it also requires large amount of water, has high chemical reaction rate and has dilatation behavior. The hydration of the particle surface of lime will start when mixing with water, and it will produce calcium hydroxide $\left(\mathrm{Ca}(\mathrm{OH})_{2}\right)$ which will be dissociated into calcium ion $\left(\mathrm{Ca}^{2+}\right)$ with positive charge and hydroxyl ion $\left(\mathrm{OH}^{-}\right)$with negative charge. This process provides large amount of calcium ion $\left(\mathrm{Ca}^{2+}\right)$ for the production of cementing ettringite $(\mathrm{AFt})$ in the process of hydration of cementing materials.

$$
\mathrm{Ca}(\mathrm{OH})_{2} \rightarrow \mathrm{Ca}^{2+}+2 \mathrm{OH}^{-}
$$

The chemical composition of the lime which was used in this research are listed in Table 1.

Table 1 Chemical Composition of the Lime

Gypsum

\begin{tabular}{cccccccc}
\hline Composition & $\mathrm{CaO}$ & $\mathrm{Al}_{2} \mathrm{O}_{3}$ & $\mathrm{Fe}_{2} \mathrm{O}_{3}$ & $\mathrm{SiO}_{2}$ & $\mathrm{MgO}$ & $\mathrm{Na}_{2} \mathrm{O}$ & $\mathrm{K}_{2} \mathrm{O}$ \\
\hline Content [\%] & 74.5 & 0.955 & 0.296 & 2.74 & 1.38 & 0.0499 & 0.128 \\
\hline Composition & $\mathrm{P}_{2} \mathrm{O}_{5}$ & $\mathrm{TiO}_{2}$ & $\mathrm{SO}_{3}$ & $\mathrm{~N}$ & $\mathrm{~F}$ & $\mathrm{MnO}$ & \\
\hline Content [\%] & 0.0099 & 0.0513 & 0.213 & 0.895 & 0.384 & 0.0201 & \\
\hline
\end{tabular}

Gypsum are mainly composed by single calcium sulfate $\left(\mathrm{CaSO}_{4}\right)$ and it has various forms of crystal structure due to different temperature and condition of dehydration. Gypsum are mainly used for adjust the time of condensation in new cementing materials ${ }^{[4]}$. The gypsum used in this research was $\beta$-semi-hydrated gypsum $\left(\beta-\mathrm{CaSO}_{4} \cdot 1 / 2 \mathrm{H}_{2} \mathrm{O}\right)$ and its chemical composition are listed in Table 2.

Table 2 Chemical Composition of the Gypsum

\begin{tabular}{cccccccc}
\hline Composition & $\mathrm{SiO}_{2}$ & $\mathrm{Fe}_{2} \mathrm{O}_{3}$ & $\mathrm{Al}_{2} \mathrm{O}_{3}$ & $\mathrm{CaO}$ & $\mathrm{MgO}$ & $\mathrm{SO}_{3}$ & $\mathrm{CaSO}_{4}$ \\
\hline Content [\%] & 1.02 & 1.34 & 0.15 & 39.63 & 1.08 & 55.04 & 93.57 \\
\hline
\end{tabular}

Smelting Residue

Smelting residues are created by blast furnace iron-making or steel-making. Gangues in ores, ashes in coke, cosolvent and other impurity which cannot be extracted with pig iron will become slag [5], mainly silicates and aluminates, flouting on iron melt when the temperature of the furnace reach up to $1400^{\circ} \mathrm{C} \sim 1600^{\circ} \mathrm{C}$ and the furnace charge melted. Smelting residue is a hydraulic cementing material which can be used as excellent raw material of filling cementing material with activating agent such as lime and gypsum. The chemical composition of the smelting residue which was used in this research are listed in Table 3.

Table 3 The Chemical Composition of the Smelting Residue

\begin{tabular}{cccccccc}
\hline Composition & $\mathrm{SiO}_{2}$ & $\mathrm{Al}_{2} \mathrm{O}_{3}$ & $\mathrm{Fe}_{2} \mathrm{O}_{3}$ & $\mathrm{CaO}$ & $\mathrm{MgO}$ & $\mathrm{Na}_{2} \mathrm{O}$ & $\mathrm{K}_{2} \mathrm{O}$ \\
\hline Content [\%] & 26.1 & 12.4 & 0.24 & 39.0 & 7.99 & 0.384 & 0.520 \\
\hline Composition & $\mathrm{P}_{2} \mathrm{O}_{5}$ & $\mathrm{TiO}_{2}$ & $\mathrm{BaO}$ & $\mathrm{B}_{2} \mathrm{O}_{3}$ & $\mathrm{SO}_{3}$ & $\mathrm{~N}$ & $\mathrm{MnO}$ \\
\hline Content [\%] & 0.0091 & 0.689 & 0.110 & 2.17 & 2.38 & 0.714 & 0.260 \\
\hline
\end{tabular}

Additives

Additives in cementing materials are mainly used for activating, coagulating acceleration, early strengthen and dilatation. The additive used in this research is independently developed complex additive. It is mainly for activate smelting residue and increase backfill strength and dilate the backfill with foaming agent.

Filling Aggregate

Most filling aggregate are industrial residue such as tailing and fly ash which is used in this research as filling aggregate. Fly ash is potentially cementitious because it can be resolved and create $\mathrm{Al}^{+3}$, which will increase the concentration of $\mathrm{Al}^{+3}$ so that $\mathrm{Al}^{+3}$ can combine with $\mathrm{Ca}^{2+}$ and $\mathrm{SO}_{4}{ }^{2-}$ to become ettringite (AFt) [6]. Meanwhile, at the beginning of the hydration of cementing material, the particle 
surface of fly ash can facilitate the forming of C-S-H and it can accelerate the hydration of $\mathrm{C}_{3} \mathrm{~S}$ to increase the strength of backfill in early stage [7].

\section{Mechanism of Dilatation and Solidification}

\section{Mechanism of Solidify}

The solidify of cementing material refers to the process of forming the strength of cementing material by hydration, coagulation and hardening [8]. Of which, the main factor for the strength of backfill are the extent of hydration, types and quality of hydration products. The hydration products of new filling cementing material are mainly ettringite (AFt) [9], and its chemical formula are : $3 \mathrm{CaO} \cdot \mathrm{Al}_{2} \mathrm{O}_{3} \cdot 3 \mathrm{CaSO}_{4} \cdot 32 \mathrm{H}_{2} \mathrm{O}$. The hydration mechanism is that minerals like $\beta$-dicalcium-silicate, anhydrous calcium sulphoaluminate $\left(3 \mathrm{CaO} \cdot 3 \mathrm{Al}_{2} \mathrm{O}_{3} \cdot \mathrm{CaSO}_{4}\right)$, lime $(\mathrm{CaO})$ and $\beta$-semi-hydrated gypsum $\left(\beta-\mathrm{CaSO} 4 \cdot 1 / 2 \mathrm{H}_{2} \mathrm{O}\right)$ will rapidly be hydrated when resolving in water and will become large amount of ettringite (Aft). The details of this reaction are as follow [10,11]:

$$
\begin{aligned}
& 3 \mathrm{CaO} \cdot 3 \mathrm{Al}_{2} \mathrm{O}_{3} \cdot \mathrm{CaSO}_{4}+18 \mathrm{H}_{2} \mathrm{O}=3 \mathrm{CaO} \cdot \mathrm{Al}_{2} \mathrm{O}_{3} \cdot \mathrm{CaSO}_{4} \cdot 12 \mathrm{H}_{2} \mathrm{O}+2\left(\mathrm{AH}_{3} \cdot 3 \mathrm{H}_{2} \mathrm{O}\right) \\
& 3 \mathrm{CaO} \cdot 3 \mathrm{Al}_{2} \mathrm{O}_{3} \cdot \mathrm{CaSO}_{4}+2 \mathrm{CaSO}_{4}+38 \mathrm{H}_{2} \mathrm{O}=3 \mathrm{CaO} \cdot \mathrm{Al}_{2} \mathrm{O}_{3} \cdot 3 \mathrm{CaSO}_{4} \cdot 32 \mathrm{H}_{2} \mathrm{O}+2\left(\mathrm{AH}_{3} \cdot 3 \mathrm{H}_{2} \mathrm{O}\right)
\end{aligned}
$$

From the equation of chemical reaction above we can observe that anhydrous calcium sulphoaluminate $\left(3 \mathrm{CaO} \cdot 3 \mathrm{Al}_{2} \mathrm{O}_{3} \cdot \mathrm{CaSO}_{4}\right)$ will be hydrated and turned into alumina gel $\left(\mathrm{AH}_{3} \cdot 3 \mathrm{H}_{2} \mathrm{O}\right)$ in lack of $\mathrm{CaO}$. However, with sufficient lime and gypsum, anhydrous calcium sulphoaluminate can be fully hydrated and become ettringite [12]. The equation of chemical reaction are as follow:

$$
\begin{aligned}
& 3 \mathrm{CaO} \cdot 3 \mathrm{Al}_{2} \mathrm{O}_{3} \cdot \mathrm{CaSO}_{4}+8 \mathrm{CaSO}_{4}+6 \mathrm{CaO}+96 \mathrm{H}_{2} \mathrm{O} \\
& =3\left(3 \mathrm{CaO} \cdot \mathrm{Al}_{2} \mathrm{O}_{3} \cdot 3 \mathrm{CaSO}_{4} \cdot 32 \mathrm{H}_{2} \mathrm{O}\right)
\end{aligned}
$$

Ettringite can also be turned into monosulfur-hydrate calcium sulphoaluminate $\left(3 \mathrm{CaO} \cdot 3 \mathrm{Al}_{2} \mathrm{O}_{3} \cdot \mathrm{CaSO}_{4} \cdot 12 \mathrm{H}_{2} \mathrm{O}\right)$ with insufficient lime and gypsum. And alumina gel, if it will be generated, it will react with lime and will be turned into hydrate calcium aluminates $\left(\mathrm{C}_{4} \mathrm{AH}_{13}\right)$. The equation of chemical reaction are as follow:

$$
\begin{aligned}
& 3 \mathrm{CaO} \cdot 3 \mathrm{Al}_{2} \mathrm{O}_{3} \cdot \mathrm{CaSO}_{4}+8 \mathrm{CaSO}_{4}+8 \mathrm{CaO}+38 \mathrm{H}_{2} \mathrm{O} \\
& =3 \mathrm{CaO} \cdot \mathrm{Al}_{2} \mathrm{O}_{3} \cdot \mathrm{CaSO}_{4} \cdot 12 \mathrm{H}_{2} \mathrm{O}+2\left(4 \mathrm{CaO} \cdot \mathrm{Al}_{2} \mathrm{O}_{3} \cdot 13 \mathrm{H}_{2} \mathrm{O}\right)
\end{aligned}
$$

Lime and gypsum will be hydrated separately and will affect the crystal structure of ettringite, due to main minerals contain $\mathrm{Al}_{2} \mathrm{O}_{3}$ have completely been hydrated and turned into ettringite with excessive lime and gypsum. Therefore, lime and gypsum need to be added properly in raw material in order to make sure all minerals can be completely hydrated into ettringite crystal of optimized structure.

Analyzing the Theory of High Water Retention

According to the molecular formula of ettringite we can see that each ettringite molecule can be generated with 32 hydrone, which is mainly why the new filling cementing material has high water retention behavior. Besides, the hardenite generated by hydration has poly-phase cellular structure, therefore it can be rapidly hydrated and release hydration heat and generate acicular and columnar ettringite crystal which will be intersected and form a steady reticular network when cementing material stirring with water. The network contains large amount of crystal water and it can absorb large amount free water like a sponge [13]. Sequentially, fiberous C-S-H gel, alumina gel and C-A-S-H gel will be formed and will be constantly increased and intersected into network so that the structure will be compacted and strength will be improved. Water will fill the pore of the network and will form a tier of hydration product clad on the surface of the network to seal three forms of water inside the network (absorbed water, crystal water and combined water). As a result, the strength of the material will reach up to maximum value. Fig. 1 is the hardenite of the material in 14th day of hydration and it is explicit to observe the clad on the surface of the network. 


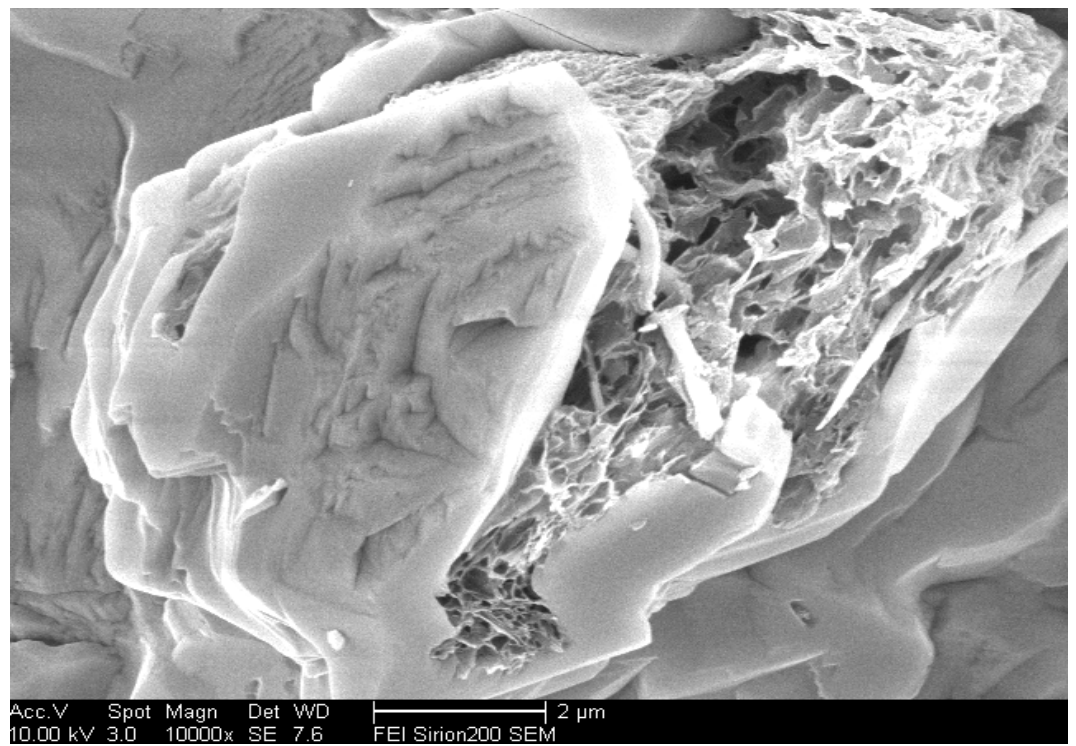

Fig. 1 Poly-Phase Cellular Structure of hardenite of High Water Retention and Dilatation Material Dilatation Mechanism

The additives in cementing materials contain some foam agent which will be uniformly distributed inside filling slurry when mixing with all raw filling materials. The mixing slurry will generate a strongly alkaline solution environment in which additives will create micro bubble. According to the characters of the filling materials slurry, those micro bubbles inside would be fixed in its original position instead of combine with other bubble into larger one or move endwise to extricate from the slurry. As a result, the slurry would dilate gradually in a short term. The generation of cellular structure of the slurry are four steps: releasing of gas, generating of bubbles, dilatation of slurry and stiffing and densification of slurry.

Quantity of foam agent in additives determine directly the number and volume of bubbles and sequentially decide the scale of the dilated backfill. Excessive foam agent will cause the extricating of bubbles from the backfill. Different impact on backfill by different quantity of foam agent are illustrated in Fig. 2 and Fig. 3.

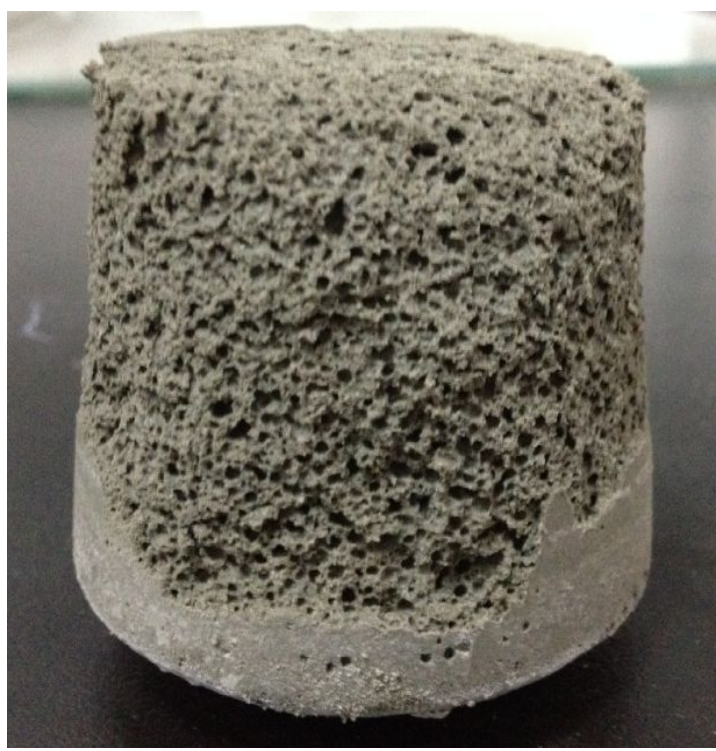

Fig. 2 is what the dilatation of the backfill was like when foam agent are $0.8 \%$ of cementing material

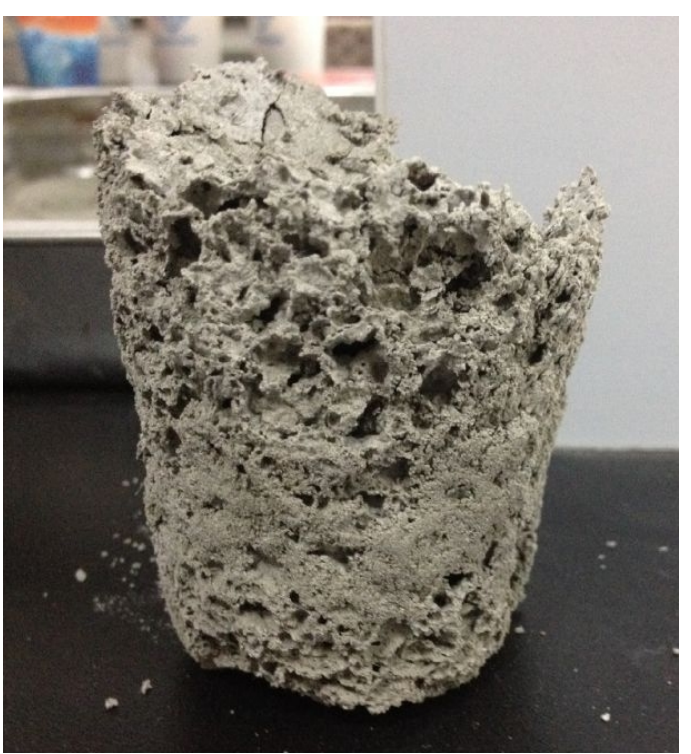

Fig. 3 is what the dilatation of the backfill was like when foam agent are $1.7 \%$ of cementing material 


\section{Experiments for High Water Retention and Dilatation Test}

\section{Water Retention Test}

With certain formulation, factors can impact water retention of the cementing material would be its fineness. Therefore, this paper conducted an experiment to show the impact on water retention behavior by fineness of the cementing material. Fineness of cementing material were $-74 \mu \mathrm{m},-45 \mu \mathrm{m}$, $-38 \mu \mathrm{m}$ and the result of water-solid ratio (mass ratio) were respectively $2.68,2.76,3: 1$. The result of three groups in this test, as you can see from Fig. 4.

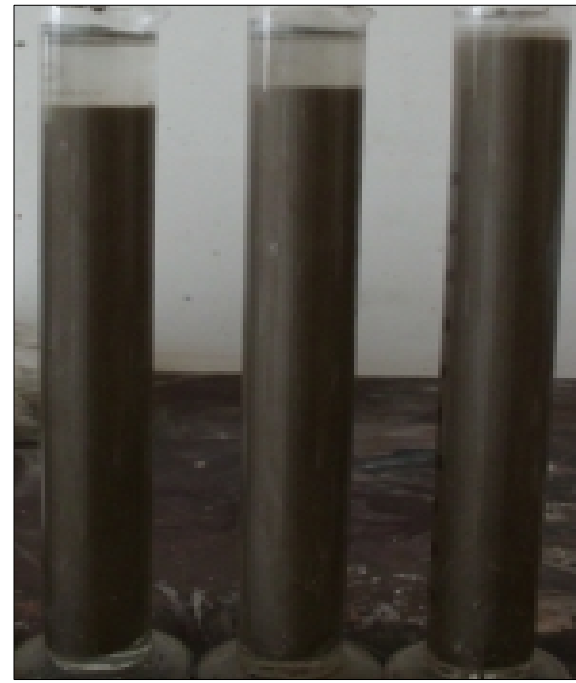

Fig. 4 Water Retention Behavior

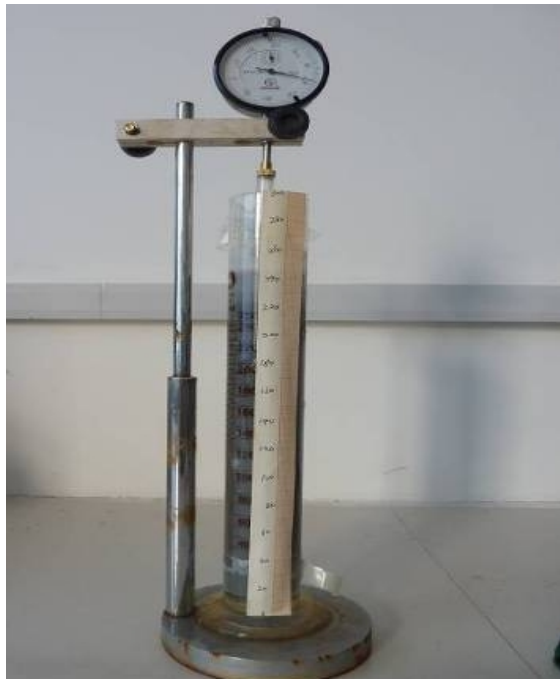

Fig. 5 Self-made Dilatation Rate Measuring Device

Dilatation Test

In order to measure dilatation rate of the filling material slurry, a new mixed slurry in a specific volume was curing in an environment with temperature of $20^{\circ} \mathrm{C}$ and moisture $90 \%$. According to measure dilatation rate of the filling material slurry after a certain period of time (a certain time during the time that mixing slurry and slurry being completely stiffing) so that the dilatation behavior can be measured. As showing in Fig. 5, the measurement device was composed by cylinder, ruler, scaffold and dial gauge.

Dilatation rate can be calculated as follow:

$$
E_{x}=\frac{L_{x}-L_{0}}{L_{0}} \times 100 \%
$$

In this equation:

$\mathrm{Ex}$ —Dilatation rate of the filling material slurry in a specific time, Unit: \%

Lx — Length readings of the filling material slurry in a specific time, Unit: $\mathrm{mm}$

$\mathrm{L}_{0}-$ Original length readings of the filling material slurry, Unit: $\mathrm{mm}$

The details in this test are as follow: the aggregate were fly ash, cementing material were independently researched high water retention and dilatation material, cementing material contain $15 \%$ of aggregate. The water was mining production water, the concentration of filling slurry was $50 \%$ and additives were $0.2 \%$ to $1.5 \%$ of cementing material. There were 11 group of samples which were tested 3 times repeatedly and respectively. The result of dilatation rate was the average value of the result of all three times tests. The test need would be re-conducted if the extremely difference of the result of dilatation rate were higher than $0.03 \%$. Table 4 for the results of this test. 
Table 4 Result of Dilatation Rate Test Unit: [\%]

\begin{tabular}{cccccccccccc}
\hline \multirow{2}{*}{ TIME } & \multicolumn{10}{c}{ VOLUME OF FOAM AGENT [\%] } \\
\cline { 2 - 14 } & 0.2 & 0.3 & 0.4 & 0.5 & 0.6 & 0.7 & 0.8 & 1.0 & 1.2 & 1.4 & 1.5 \\
\hline $0.5 \mathrm{~h}$ & 3.02 & 4.92 & 8.01 & 10.02 & 11.45 & 13.14 & 16.77 & 20.76 & 22.51 & 24.02 & 26.66 \\
$1 \mathrm{~h}$ & 4.98 & 7.84 & 10.58 & 15.12 & 17.93 & 20.31 & 19.83 & 26.13 & 27.47 & 32.10 & 34.18 \\
$3 \mathrm{~h}$ & 5.72 & 10.34 & 15.25 & 20.08 & 21.90 & 25.89 & 24.17 & 34.22 & 36.38 & 44.21 & 47.52 \\
\hline $6 \mathrm{~h}$ & 7.89 & 12.11 & 19.01 & 23.99 & 22.67 & 27.12 & 28.61 & 37.14 & 41.33 & 45.24 & 50.69 \\
$12 \mathrm{~h}$ & 9.12 & 13.82 & 20.42 & 24.73 & 22.72 & 27.12 & 30.78 & 38.93 & 42.49 & 46.32 & 51.02 \\
$1 \mathrm{~d}$ & 9.23 & 13.87 & 20.43 & 24.89 & 22.72 & 27.12 & 30.78 & 38.93 & 42.49 & 46.32 & 51.02 \\
\hline
\end{tabular}

According to the experiment result, dilatation rate increase with additives volume and both of them became steady. The dilatation rate in the first $0.5 \mathrm{~h}$ in a unit time were fastest.

\section{Characteristics of Strength of the backfill}

In this experiment, the uniaxial stress resistance, tensile strength and flexural strength of backfill with different curing period were tested. Dilatation rate of each samples were the same. The mass concentrations of tested filling material slurry were $45 \%$ and $50 \%$, additive volume of cementing material were $10 \%, 12 \%$ and $15 \%$, testing period were $1 \mathrm{~d}, 3 \mathrm{~d}, 7 \mathrm{~d}, 14 \mathrm{~d}, 28 \mathrm{~d}, 60 \mathrm{~d}$. Details of the testing result are listed in Table 5.

Table 5 Table for Strength testing of filling materials

\begin{tabular}{|c|c|c|c|c|c|c|c|c|}
\hline \multirow{2}{*}{$\begin{array}{c}\text { Fly Ash } \\
\text { Concentration } \\
{[\%]}\end{array}$} & \multirow{2}{*}{$\begin{array}{c}\text { Additive } \\
\text { Volume } \\
{[\%]}\end{array}$} & \multirow[b]{2}{*}{ Item } & \multicolumn{6}{|c|}{ Curing Period [d] } \\
\hline & & & 1 & 3 & 7 & 14 & 28 & 60 \\
\hline \multirow{9}{*}{45} & \multirow{3}{*}{10} & StressResistance & 0.76 & 1.03 & 1.96 & 3.93 & 5.06 & 5.60 \\
\hline & & Tensile Strength & 0.10 & 0.31 & 0.39 & 0.52 & 0.73 & 0.85 \\
\hline & & FlexuralStrenght & 0.30 & 0.55 & 1.01 & 1.67 & 1.88 & 2.06 \\
\hline & \multirow{3}{*}{12} & StressResistance & 1.09 & 1.42 & 2.25 & 4.09 & 5.46 & 7.26 \\
\hline & & Tensile Strength & 0.17 & 0.35 & 0.55 & 0.81 & 0.83 & 0.91 \\
\hline & & FlexuralStrenght & 0.39 & 0.75 & 1.20 & 1.69 & 1.96 & 2.16 \\
\hline & \multirow{3}{*}{15} & StressResistance & 1.25 & 1.62 & 3.71 & 4.41 & 5.50 & 7.64 \\
\hline & & Tensile Strength & 0.17 & 0.39 & 0.60 & 0.83 & 0.90 & 1.03 \\
\hline & & FlexuralStrenght & 0.49 & 0.78 & 1.57 & 1.95 & 2.30 & 2.40 \\
\hline \multirow{9}{*}{50} & \multirow{3}{*}{10} & StressResistance & 1.43 & 2.59 & 3.59 & 6.02 & 7.50 & 8.90 \\
\hline & & Tensile Strength & 0.31 & 0.53 & 0.86 & 0.93 & 1.16 & 1.19 \\
\hline & & FlexuralStrenght & 0.63 & 1.10 & 1.71 & 2.03 & 2.46 & 2.81 \\
\hline & \multirow{3}{*}{12} & StressResistance & 1.63 & 2.76 & 5.37 & 6.10 & 7.96 & 9.48 \\
\hline & & Tensile Strength & 0.33 & 0.61 & 0.91 & 0.95 & 1.17 & 1.37 \\
\hline & & FlexuralStrenght & 0.72 & 1.32 & 1.85 & 2.30 & 2.77 & 3.07 \\
\hline & \multirow{3}{*}{15} & StressResistance & 1.82 & 2.92 & 5.76 & 6.27 & 7.84 & 9.73 \\
\hline & & Tensile Strength & 0.35 & 0.67 & 0.96 & 1.12 & 1.28 & 1.41 \\
\hline & & FlexuralStrenght & 0.82 & 1.48 & 1.99 & 2.35 & 2.82 & 3.19 \\
\hline
\end{tabular}

According to the test, curve of relationship between stress resistance, tensile strength and flexural strength are demonstrated in Fig. 6 and 7. 


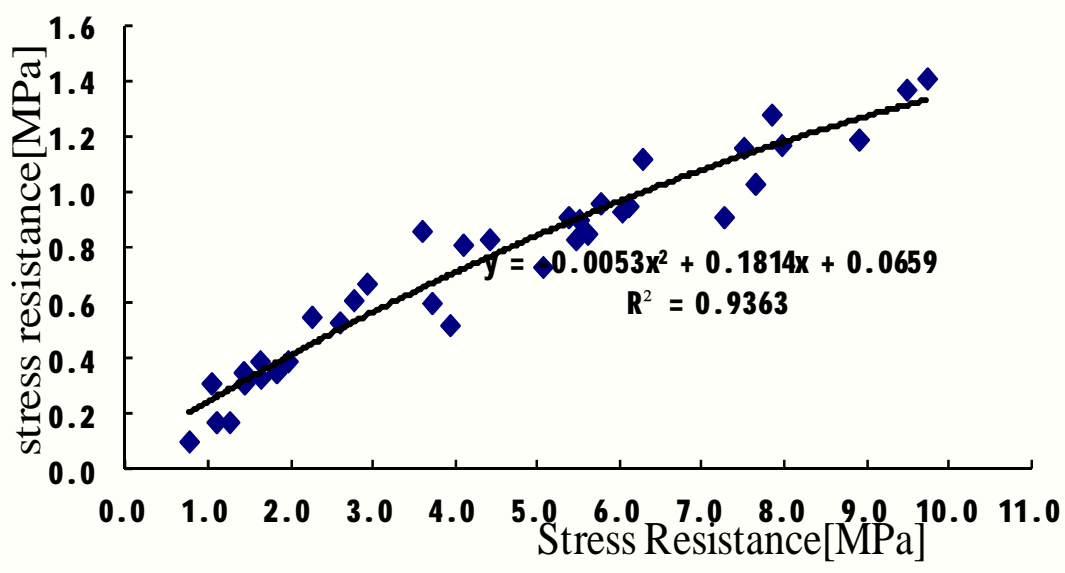

Fig. 6 Curve of relationship between stress resistance and tensile strength

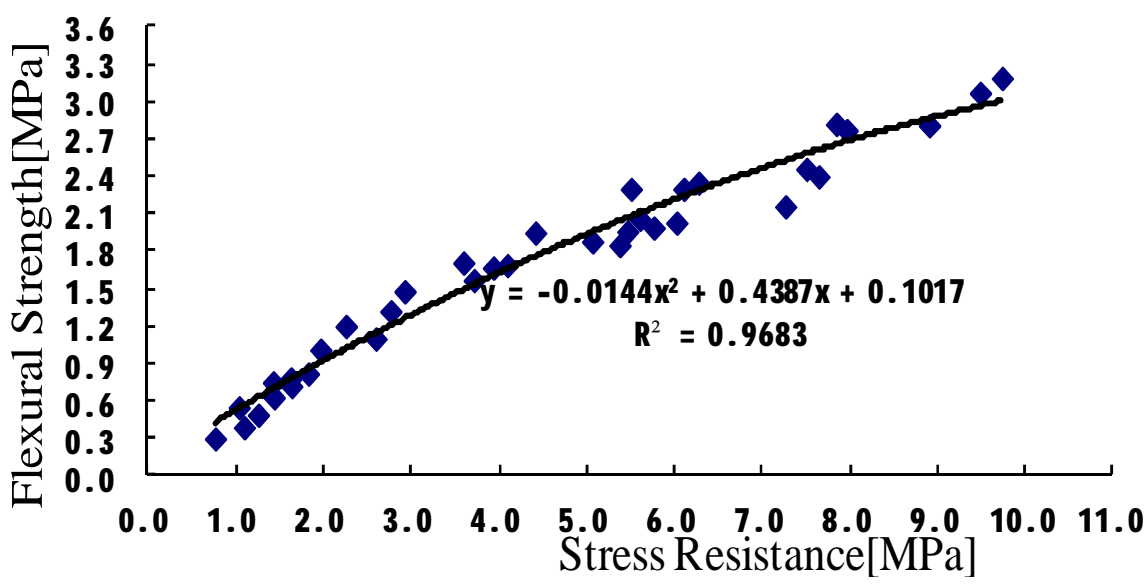

Fig. 7 Curve of relationship between stress resistance and flexural strength

According to the result of table 5, Fig. 6 and Fig. 7, the strength of filling material increased with curing period. The growth rate is higher in early stage and slowed down after 28 days. The cementing material additive volume are in proportion to the strength in same concentration and the strength disparity will be almost curtailed after 28 days.

Analyzing Fig. 6, Fig. 7 by ordinary least-square, the function of relation between tensile strength $\left(\mathrm{P}_{1}\right)$, flexural strength $\left(\mathrm{P}_{2}\right)$ and stress resistance $\left(\mathrm{P}_{0}\right)$ were respectively $\mathrm{P}_{1}=-0.0053 \mathrm{P}_{0}^{2}+0.1814 \mathrm{P}_{0}+$ 0.0659、 $\mathrm{P}_{2}=-0.0144 \mathrm{P}_{0}^{2}+0.4387 \mathrm{P}_{0}+0.1017$. It proved that tress resistance are in proportion with tensile strength and flexural strength, whereas the growth rate of stress resistance is higher than those of tensile strength and flexural strength. According to the relation function, it is explicit that with knowing the stress resistance, tensile strength and flexural strength can be calculated.

\section{Analyzing Micro-Structure of Filling Material}

Observing the micro-structure of backfill with concentration of $50 \%$ and contain $12 \%$ of cementing material and $0.3 \%$ additive in 7 days, 14 days, 28 days and 60 days by Scanning Electron Microscope(SEM). The results are showed in Fig. 8 to Fig. 11. 


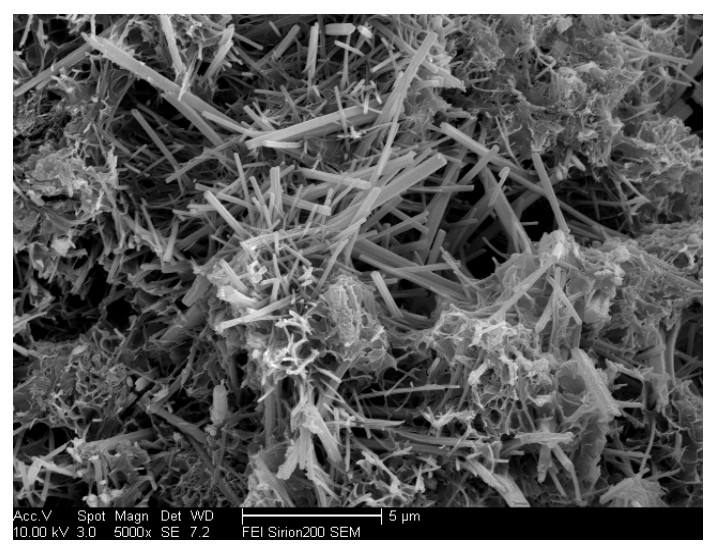

Fig. 8 Backfill in 7th curing day observed

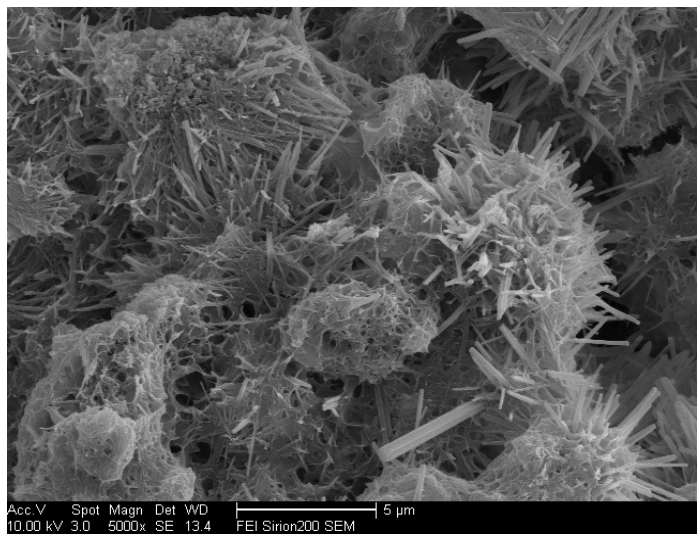

Fig. 9 Backfill in 14th curing day observed

In the early stage of hydration, acicular and columnar ettringite crystal were generated and intersecting steady network were formed. During 3rd day to 7 th day, the filling material backfill slurry have formed complete network. The length of ettringite crystal were $10 \mu \mathrm{m}$ and the fineness were $1 \mu \mathrm{m}$ and they were intersected. After 7 days, ettringite crystal grew in larger space centered in primitive particle and spread in radiance pattern. C-S-H gel and rod like ettringite crystal have formed on the surface of the crystal by then. After 14 days, C-S-H gel and C-A-H gel were formed, increased and clad ettringit and form a compact network to condense the structure and increase the strength of the crystal.

According to the strength test we can see that the strength of filling material was influenced by ettringite. As the curing period goes, C-S-H gel and C-A-H gel were formed were formed, grew, intersected and uniformly attached to cementing material such as ettringite formed in the previous stage to increase the uniformity and compactness. Stress resistance, tensile strength and flexural strength of the filling material were increased due to uniform internal structure.

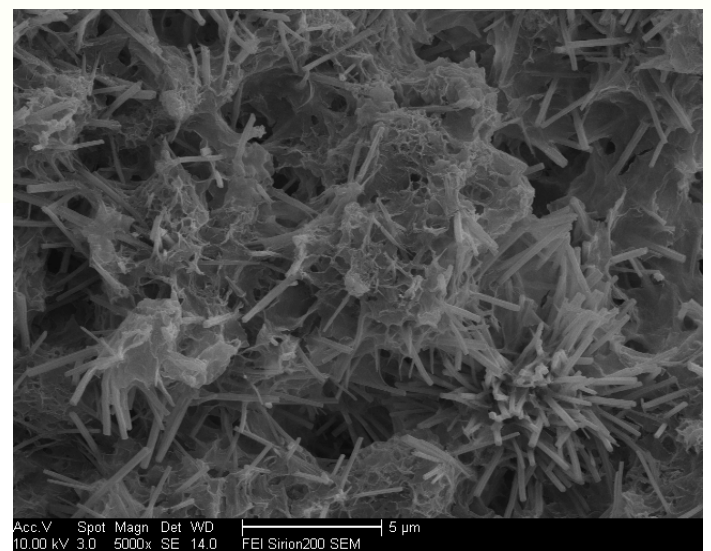

Fig.10 Backfill in 28th curing day observed

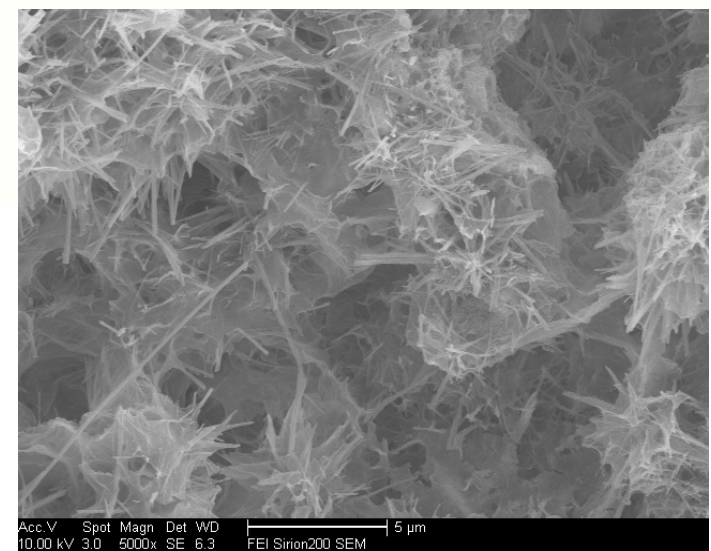

Fig.11 Backfill in 60th curing day observed

\section{Conclusions}

By analyzing dilatation and solidify mechanism, conducting water retention and dilatation test, strength test and by analyzing micro-structure of the high water retention and dilatation new filling cementing material, we can draw the conclusion as follow:

1) The products of hydration of cementing material in early stage are ettringite, and each ettringite molecule can be generated with 32 hydrone, which is mainly why the new filling cementing material has high water retention behavior. The water retention test has proved that the maximum water-solid rate can reach up to $3: 1$. 
2) Foam agent in additives which added in backfill can make the backfill dilated. When additives are account for $0.2 \%$ to $1.5 \%$ of cementing material, the dilatation rate are $9.23 \%$ to $51.02 \%$.

3 ) According to the strength test: strength grows with curing period. The grow rate in previous stage are comparatively higher and the grow rate will be curtailed after 28 days. The cementing material additive volume are in proportion to the strength in same concentration and the strength disparity will be almost curtailed after 28 days.

4) Analyzing by ordinary least-square, the function of relation between tensile strength $\left(\mathrm{P}_{1}\right)$, flexural strength $\left(\mathrm{P}_{2}\right)$ and stress resistance $\left(\mathrm{P}_{0}\right)$ were respectively $\mathrm{P}_{1}=-0.0053 \mathrm{P}_{0}{ }^{2}+0.1814 \mathrm{P}_{0}+$ 0.0659、 $\mathrm{P}_{2}=-0.0144 \mathrm{P}_{0}^{2}+0.4387 \mathrm{P}_{0}+0.1017$. It proved that tress resistance are in proportion with tensile strength and flexural strength, whereas the growth rate of stress resistance is higher than those of tensile strength and flexural strength.

5) According to the strength test we can see that the strength of filling material was influenced by ettringite. After 7 days, ettringite crystal grew in larger space centered in primitive particle and spread in radiance pattern. C-S-H gel and rodlike ettringite crystal have formed on the surface of the crystal by then. After 14 days, C-S-H gel and C-A-H gel were formed, increased and clad ettringit and form a compact network to condense the structure and increase the strength of the crystal. The strength will reach its peak till 28th day.

\section{References}

[1] X. Wang. The Technology and Theory of Deep Mining and Backfill mining. Changsha: Central South University Press, 2005:57-63

[2] M. Qian. Conception and Technology System of Green Mining. Coal Science and Technology Magazine, 2003,4:1-3

[3] Q. Pei. Main Influence and Control Methods of Quality of Cementing Filling Material. Modern Mining Magazine,2009,5:99-102

[4] J. Peng, F. Lin. Research of Cementing Materials-Dihydrate Gypsum and Fly Ash. Concrete and Cement Products, 1995, (6):16-19

[5] J. Wang. Generation and Overall Untilization of Solid Residue of Steel Industry. Environmental Protection and Circular Economy,2012,3:40-41

[6] F. Wei, M.W. Grutzeck, D.M. Roy. The retarding effect of fly ash upon the hydration of cement Paste: the first 24 hours. Cem Concr Res,1985,15(1):174-184

[7] H.F. Taylor. Cement Chemistry. London: Thomas Telford Publishing, 1997. 275

[8] J. SHI. Research and Application of Dilatation Behavior of Filling Material Slurry. Xuzhou: China University of Mining and Technology Press,2013:53-54

[9] A.M. Cody, H. Lee, R.D. Cody, et al., The effects of chemical environment on the nucleation, growth,and stability of ettringite $\left[\mathrm{Ca}_{2} \mathrm{Al}(\mathrm{OH})_{6}\right] 2\left(\mathrm{SO}_{4}\right) 3 \cdot 26 \mathrm{H}_{2} \mathrm{O}$, Cement and Concrete Re-search,2004,34:869-881

[10] P.C. Hewlett, ed., Lea's Chemistry of Cement and Concrete, 4th ed., Arnold, London, $1053 \mathrm{p}, 1998$

[11] J. Newman, B.S. Choo ,eds.Advanced Concrete Technology: Constituent Materials, Butterworth-Heinemann, Oxford, 2003

[12] Y. Fu, J. Wang. Research of Backfill Behavior of Silicate Cement Contain C4A3S Mineral. Mining and Metallurgy. 2009,18(4):4-8 
[13] J. Shi. Technology of High Dilatation Material and Cementing Filling. Jinan. Shandong Science and Technology Press,2011,57-58 